\title{
Study on the Cutting Efficiency of High-Speed Band Saw Blade by Taylor Tool Life and Fractal Equations
}

\author{
Sung-Hua $\mathrm{Wu}^{l, *}$, Ming-Shyan Huang ${ }^{l}$, Cheng-En Jhou ${ }^{l}$, and Chin-Chung Wei ${ }^{2}$ \\ ${ }^{1}$ Department of Mechanical and Automation Engineering, National Kaohsiung First University of Science and Technology, No.1 \\ Chuangxin Road,811 Kaohsiung, Taiwan \\ ${ }^{2}$ Department of Power Mechanical Engineering, National Formosa University, No.64 Wenhua Road,632 Yunlin, Taiwan
}

\begin{abstract}
The study proposed the chip formation steady-state model and cutting efficiency model for multi-cutters by Taylor tool life and fractal equation according to uniform chip thickness in high-speed band sawing process. Furthermore, a kind of new hook-tooth can be successfully applied on continuously uniformed chip formation in order to raise the production precision. The study developed MDOF cutting dynamics, which can be applied on multi-cutting process by Taylor tool life and fractal equations. Factors of affecting band-sawing included the cutting force, the cutting geometry, the cutting heat, the local stressstrain and the chip thickness formation uniformity. These factors had an important influence on tool wear, surface roughness, production precision and cutting efficiency in high-speed sawing process. The simulated results shown that, the wear resistance property is better at coating TiN $0.6 \mu \mathrm{m}$. In high-speed cutting process, the cutting improvement rate can be increased at least $13 \%$. While the hook-tooth cutting speed achieved $120 \mathrm{~m} / \mathrm{min}$, comparing with non-coating cutting tooth, coating $0.6 \mu \mathrm{m}$ coating-layer can make the temperature decreased, obviously.
\end{abstract}

\section{Introduction}

Factors of affecting band-sawing include cutting force, cutting geometry, cutting heat, local stress-strain and chip thickness formation uniformity. These factors have an important influence on tool wear, surface roughness, production precision and cutting efficiency in high-speed sawing process. It is effective to improve machining quality, raise cutting efficiency and reduce the cost by controlling these factors. The study proposed cutting factors of tool geometry in band-sawing process, simulated and improved the machining characteristics and investigated the effects of vary kinds of cutters geometry in sawing process. By using the optimal process parameters, including coating factors, cutting velocity, tool geometry, tool material and workpiece material to improve cutting temperature, cutting resistance and the production qualities will achieve a better standard.

\subsection{Paper Review}

Band-saw types can be distinguished from the straightcutters, wave-cutters, sinusoidal-cutters, circle-cutters and wire-saw depended on saw-blade geometry, and machining mechanism applied on multi-points cutting. According to the band-saw with different kinds of sawblade, it can be processing on metal, wood, plastic material and even in semi-conductive chip. Earlier studies, there were a lot of papers investigated about band-sawing process. According to the studies, the cutter design has greater effects on cutting process, and then, it will cause tool wear fast and bad surface roughness, especially for the tool life decreasing. Ko and Kim [1] analyzed saw-blade geometry and mechanistic cutting force prediction agreed well with experimental trends. Andersson [2-4] used the FEM demonstrated that, the maximum stress had decreasing with cutter radius increasing. The kind of tool geometry variation caused cutting force variation along feed direction and linear increasing with undeformed chip thickness. Marusich [5] et. al simulated the cutting process under residual stress with considering heat performance, tool geometry and machining parameters on workpiece. They found the relations of stress, cutting velocity and chip load. Xu and $\mathrm{Yu}$ [6] investigated sawing performance of diamond with alloy coatings, and the coating can raise the TRS performance. Okai [7] et. al used saw-blade analyzed to investigate the effects of cutting velocity and cutting force, however, the cutting tool caused wear because of cutting heat and local stress concentrated. Buyuksehir [8] investigated specific wear ratio and obtained specific energy under up-cutting modes, and determined the optimal performance between process parameters, cutting depth and workpiece moved velocity. Besides, wire-saw is another important machining application for natural stones and architecture. $\mathrm{Wu}$ [9] et. al studied multi-points by chip fractal geometry and hack-sawing mechanism, and predicted cutting force, boundary conditions, undeform cutting areas and specific energy trends, successfully. Thaler [10] et. al studied the stability diagrams and chatter avoidance in horizontal band sawing, and the experimental results the analysis of chatter avoidance is better than unstable cutting force signals. To raise the cutting efficiency and cutting velocity, the cutting stratray is to reduce chatter occurred. Patten [12] et. al used AdvanEdge to establish cutting

Corresponding author: jackywoo0923@gmail.com 
model, such as feed, edge radius, cutting depth 10 micrometer and cutting velocity $1 \sim 300 \mathrm{~m} / \mathrm{min}$. They found the toughness shearing occurred in high-speed sawing process. Usui [13] et. al proposed a kind of finite element model to calculate chip geometry, cutting force and surface hardening by applying Lagrangian method to predict AISI 4130 chip breaking. Grzesik [14] et. al used FEM the orthogonal cutting process by coating tool and uncoating tool with adding $\mathrm{TiC}$ and $\mathrm{Al}_{2} \mathrm{O}_{3}$ deposited on P20 carbo-material. Fang [15] et. al proposed the heat-elastic-plastic coupling model to simulate 3 dimensional FEM, and the results demonstrated the stress concentration on tool-edge section and the higher stress focus on the main deformation zone. Usui [16] studied 3D FEM, including adaptive meshing, heatmechanical coupling, strain rate and high temperature deformation for tool. Stephenson [17] et. al proposed 3D FEM for drilling model, including adaptive meshing, heat-mechanical coupling effect, strain rate and high temperature deformation for tool. Mohammadpour [18] et. al observed the residual stress influence of cutting velocity and feed rate in orthogonal cutting process, and the results the chip formation and stress distribution can be successfully predicted by MSC. Superform. Huang and Yang [19] indicted the energy reduced from the cutting heat in high-speed cutting process, resulted in the non-uniform heat distribution on workpiece. Fractal is a kind of mathematical tool to solve the transient problems by Mandelbrot [20], who proposed W-M fractal function in order to simplified Weieratrass equation to simulate roughness profile by topothesy and random phase.

\section{Theoretical Modelling}

The study developed MDOF cutting dynamics, which can be applied on multi-cutting process by Taylor tool life and fractal equations. The maximum material removal rate (MMR) and chip thickness uniformity were the objective functions, which simulated on S45C in order to find out the optimal geometric and process parameters in multi-points sawing process.

\subsection{MDOF Cutting Dynamics}

From Fig. 1 (a)-(e), the MDOF cutting dynamics can be established by steady-state chip formation without selfexcited vibration. In brief, the governing equation for MDOF can be written as Eq. (1)

$$
[\mathrm{M}][\ddot{x}]+[c][\dot{x}]+[k][x]=[0]
$$

Hence, Eq.(2) to Eq.(4) can be obtained as generalized matrix by conservation of energy.

$$
[\mathrm{M}]=\left[\begin{array}{ccccc}
m_{1} & 0 & 0 & \cdots & 0 \\
0 & m_{2} & 0 & \cdots & 0 \\
0 & 0 & m_{3} & \cdots & 0 \\
\vdots & \vdots & \vdots & \cdots & \vdots \\
0 & 0 & 0 & \cdots & m_{n}
\end{array}\right]
$$

$$
\begin{aligned}
& {[c]=\left[\begin{array}{ccccc}
c_{1} & c_{1}+c_{2} & 0 & \ldots & 0 \\
c_{1}+c_{2} & c_{2} & c_{2}+c_{3} & \ldots & 0 \\
0 & c_{2}+c_{3} & c_{3} & \ldots & 0 \\
\vdots & \vdots & \vdots & \ldots & c_{n-1}+c_{n} \\
0 & 0 & 0 & c_{n-1}+c_{n} & c_{n}
\end{array}\right]} \\
& {[k]=\left[\begin{array}{ccccc}
k_{1} & k_{1}+k_{2} & 0 & \cdots & 0 \\
k_{1}+k_{2} & k_{2} & k_{2}+k_{3} & \ldots & 0 \\
0 & k_{2}+k_{3} & k_{3} & \ldots & 0 \\
\vdots & \vdots & \vdots & \ldots & k_{n-1}+k_{n} \\
0 & 0 & 0 & k_{n-1}+k_{n} & k_{n}
\end{array}\right]}
\end{aligned}
$$

For furthermore, take Laplace Transform, and assumed $\{x\}=\{\bar{x}\} e^{s t}$ subinto Eq.(1)

$$
s^{2}[\mathrm{M}][\bar{x}]+s[c][\bar{x}]+[k][\bar{x}]=\{0\}
$$

Through reduced order, assumed $\{\hat{x}\}=s\{\bar{x}\}$ subinto Eq.(5), Eq.(6) can be obtained.

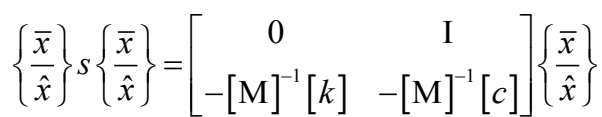

To solve the eigenvalues and egigenvectors from $2 \mathrm{n}$ set, $\left\{S_{k}\right\}_{n * 1}$ and $\left\{S_{n}^{*}\right\}_{n * 1}$, where $S_{k}=-\delta_{k}+j \omega k$, $s_{k}=-\delta_{k}-j \omega k$

The generalized displacement of cutter edge can be written as Eq.(7)

$$
\begin{aligned}
& \left\{\mathrm{X}_{k}(t)\right\}=c_{1 k} e^{S_{k t}}\left\{\mathrm{X}_{k}\right\}+c c_{2 k} e^{S_{k^{*} t}}\left\{\mathrm{X}_{k}^{*}\right\} \\
& =e^{-\delta_{k} t}\left(e^{j \omega k t} c c_{1 k}\left\{\mathrm{X}_{k}\right\}+e^{-j \omega k t}\left\{\mathrm{X}_{k}^{*}\right\}\right) \\
& =\{\mathrm{XX}\}_{k} e^{-\delta k t} \cos \left(\omega k t-\theta_{k}\right)
\end{aligned}
$$

Where $\{\mathrm{XX}\}_{k}=\sqrt{\left(c c_{1 k} \mathrm{X}_{k}+c c_{2 k} \mathrm{X}_{k}^{*}\right)^{2}-\left(c c_{1 k} \mathrm{X}_{k}-c c_{2 k} \mathrm{X}_{k}^{*}\right)^{2}}$;

$$
\theta_{k}=a \tan \left(\frac{j\left(c c_{1 k} \mathrm{X}_{k}-c c_{2 k} \mathrm{X}_{k}^{*}\right)}{c c_{1 k} \mathrm{X}_{k}+c c_{2 k} \mathrm{X}_{k}^{*}}\right)
$$

Hence, Eq.(7) can be rewritten as Eq.(9)

$$
\begin{array}{r}
\{\mathrm{X}(t)\}=\sum_{k=1}^{n}\{\mathrm{XX}\}_{k} e^{-\delta t} \cos \left(\omega k t-\theta_{k}\right) \\
d f(t) \sqrt{\gamma / \sqrt{d x^{2}+d f^{2}}}
\end{array}
$$

For a tiny displacement $d x$ at differential-cutter, the tiny feed $d f$ will be occurred at the same time $t$, hence, Eq.(10) can be derived.

$$
\gamma=\tan ^{-1}\left(\frac{d x}{d f}\right)
$$

If the chip formation is steady-state, the $\gamma$ is uaually constant, called differential-cutter angle. For two dimensional orthogonal cutting, Eq.(11) can be expressed MDOF cutting from every single unit cutter.

$$
\int_{0}^{l}\{X(t)\} d x=\int_{0}^{h} \tan (\gamma) d f
$$


Where $l$ means the cutting length from the workpiece, and $h$ means the average cutting depth. For furthermore, the transient chip load for every single cutters can be derived from feed $d f(t)$, cutting width $b$ and cutting overlap ratio $\alpha$ from chip fractal geometry. Average specific energy $\mathrm{K}_{t}$ can be obtained through unit cutting areas of multi-cutters as Eq.(12)-Eq.(15)

$$
\mathrm{K}_{\mathrm{t}}=\frac{W}{\Delta V}
$$

For single cutters,

$$
W=\mathrm{K}_{\mathrm{t}} V_{s}=\mathrm{K}_{\mathrm{t}} L A_{s}
$$

For multi-cutters,

$$
W=\mathrm{K}_{\mathrm{t}} V=\mathrm{K}_{\mathrm{t}} \sum_{i=1}^{n} A_{i} l_{i}
$$

The study denotes average sprcific energy Kt and average cutting force for multi-cutters,

$$
\bar{F}=\overline{\mathrm{K}}_{\mathrm{t}}\left(\sum_{i=1}^{n} a_{i}\right)
$$

\subsection{Fractal Differential Equation}

In order to obtain chip fractal self-similarity, the cutting tool can be expressed as sinusoidal-wave through onedimensional projection and become 84 cutter topologies. According to sinusoidal multi-cutters, the cutters interference ratio of cutter arrangement can be written as Eq. (16).

$$
\alpha_{n+1}=1-\frac{\lambda}{n \cdot b}\left(\tan \theta_{n+1}-\tan \theta_{n}\right)
$$

Where $\alpha_{n+1}$ means $(n+1)^{\text {th }}$ cutter; $\lambda$ denotes the length of unit wave; $\mathrm{n}$ means cutter number of period; $b$ means cutter width; ${ }_{n+1}$ means the banding angle of unit cutter. The equivalent depth under cutter interference in cutting process can be demonstrated as Eq.(2) and Fig.1, called fractal- algebraic operators.

$$
d_{i, \max }=d_{1}^{*}\left(\frac{\alpha_{i}}{1-\alpha_{i}}\right)^{n-1}+\left(1-\alpha_{i}\right)\left(d_{i-1}-d_{i-2}\right)+d_{1}^{*}
$$

Where $d_{1}{ }^{*}$ means the initial cutting depth according to experimental results; $d_{i}$ means the transient cutting depth for $i^{\text {th }}$ cutter of total working cutters. To consider the chip load of the equivalent depth and cutting width in two-dimension, the chip load can be presented as Eq. (17) without energy dissipated.

$$
\begin{aligned}
& P_{i}=A_{i} \\
& =b_{i} \times d_{i} \\
& =b_{i}\left[d_{1}^{*}\left(\frac{\alpha_{i}}{1-\alpha_{i}}\right)^{n-1}+\left(1-\alpha_{i}\right)\left(d_{i-1}-d_{i-2}\right)+d_{1}^{*}\right] \\
& =\left(1-\alpha_{i}\right) b^{*}\left[d_{1}^{*}\left(\frac{\alpha_{i}}{1-\alpha_{i}}\right)^{n-1}+\left(1-\alpha_{i}\right)\left(d_{i-1}-d_{i-2}\right)+d_{1}^{*}\right]
\end{aligned}
$$

$A_{i}$ means the chip load under geometry interference, and the shape has strictly fractal self-similarity It is key point to determine the boundary orders in order to obtain exact convolution function. Due to geometric characteristics, Eq. (18) can be shown as chip-load geometric factors of cutting process, called chip load function of sinusoidal multi-cutters. Eq. (18) can be also rewritten as a functional expression as Eq. (19)

$P\left(d_{i}, \alpha_{i}, b, n, \theta_{i}\right)$

$=\left(1-\alpha_{i}\right) b^{*}\left[d_{1}^{*}\left(\frac{\alpha_{i}}{1-\alpha_{i}}\right)^{n-1}+\left(1-\alpha_{i}\right)\left(d_{i-1}-d_{i-2}\right)+d_{1}^{*}\right]$

From Eq. (19), $\tan \theta=R \sin \left(i \times \frac{2 \pi}{n}\right) / t_{p} ; R$ means

amplitude of sinusoidal-set cutters; $t_{\mathrm{p}}$ means cutter pitch

\subsection{Taylor's Tool Life and Cutting Efficiency Model}

The traditional Taylor's tool life can be demonstrated as Eq. (20)

$$
V T^{n}=C
$$

Where $n=\frac{\log \left(\frac{C}{V}\right)}{\log T}, V$ means cutting velocity and $T$ denotes the tool life, $n$ means exponent.

Extend Eq. (20), the generalized form can be rewritten as Eq. (21) for more process parameters

$$
\left[F_{c}\right]^{f}[P]^{m}[N]^{d}[f]^{q} V[T]^{n}=C_{1}
$$

Where $f$ means the cutting force exponent; $m$ means the exponent for the cutting numbers of workpieces; $d$ means the exponent of coating layer thickness; q means the exponent for feed.

Simultaneously, the raising cutting efficiency model for multi-cutters can be derived from Taylor's Tool life equation as Eq. (22)

$$
E=\eta(\%) \cdot e^{-\eta \cdot 10}
$$

Where $\mathrm{E}$ means the cutting efficiency for multicutters, and $\eta$ means the percentage of single-cutter cutting efficiency. From the simulation of single-cutter, it can be extended to the multi-cutters cutting efficiency obtained by Eq. (22)

In order to obtain the temperature variation of cutter edge and chip surface, where the Johnson-Cook equation used as Eq. (23), it assumed the temperature conduction between tool and workpiece. The study doesn't be considered cutting temperature conducting into the air.

$$
\sigma_{e q}=\left(A+B \varepsilon_{n}\right)\left(1+C \ln \left(\frac{\dot{\varepsilon}}{\dot{\varepsilon}_{0}}\right)\right)\left(1-\left(\frac{T-T_{\text {room }}}{T_{m}-T_{\text {room }}}\right)^{m}\right)
$$

Where $T_{m}$ means the melting point temperature; $T_{\text {room }}$ means the environmental temperature; $T$ means the workpiece temperature; $A$ means the yielding stress; $B$ means the strain factor; $n$ means the strain coefficient; $\mathrm{m}$ means the temperature coefficient; $\varepsilon$ means the plastic strain ratio; $\varepsilon_{0}$ means the stain ratio 


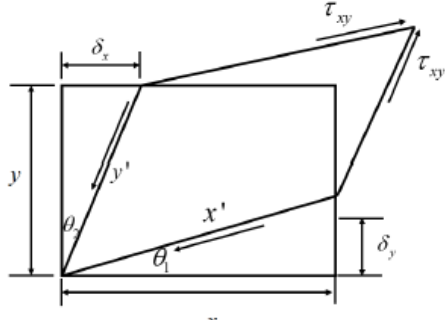

Cutting tool suffered loading will be occurred stress and strain, result in the body deformation. The strain can be distinguished from normal strain and shear strain. The physical meanings are length deformation and the variation of angle. If the model considers shear strain without normal strain, the Eq. (24) and Eq. (25) can be expressed.

$$
\begin{gathered}
\varepsilon_{x x}=\frac{x^{\prime}-x}{x}=\frac{\sqrt{x^{2}+\delta_{y}^{2}}-x}{x} \cong \frac{x-x}{x}=0 \\
\gamma_{x y}=\theta_{1}+\theta_{2} \cong \tan \theta_{1}+\tan \theta_{2}=\frac{\delta_{x}}{x}+\frac{\delta_{y}}{y}
\end{gathered}
$$

The simulation processes the band-saw orthogonal cutting by Lagrangian finite element method and numerical analysis.

\section{Results and Discussion}

The study proposed the chip formation steady-state model and cutting efficiency model for multi-cutters by Taylor tool life and fractal equation according to uniform chip thickness in high-speed band sawing process as Fig. (a)-(d). The uniformity of the study has two, one is the chip thickness uniformity, and the other is cutting temperature uniformity. Furthermore, a kind of new hook-tooth can be successfully applied on continuously uniformed chip formation in order to raise the production precision. Fig.1 (b) demonstrates a kind of hook-tooth design with coating TiN $0.2 \sim 0.6 \mu \mathrm{m}$ and uncoating simulation. Initial chip formation and mesh has good uniformity from Fig. 1 (d). H-adaptive model can cause the fine mesh to the cutting precision raising.

\section{(Multi-Degree-of-freedom cutting system)}

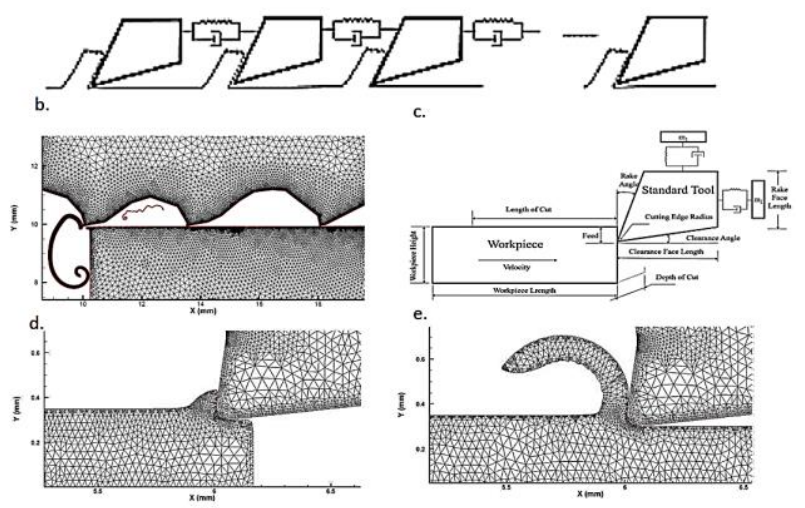

Fig.1. (a) Multi-degree-of-freedom cutting modelling; (b) chip formation for multi-cutters; (c) mathematical model for single cutter; (d) initial chip formation and mesh; (e) steady-state chip formation without considering selfexcited vibration

\subsection{Hook-Tooth Design and Simulated Parameters}

Hook-tooth design can cause the higher shear strain rate to remove the chip, and furthermore, the tool obtained the smaller cutting temperature in order to extend the tool life. Fig. 2 and Table 1 demonstrated that, the cutting temperature for the relations of variations of cutting velocity from $40 \mathrm{~m} / \mathrm{min}$ to $80 \mathrm{~m} / \mathrm{min}$ and feed rate from $45 \mathrm{~cm}^{\wedge} 2 / \mathrm{min}$ to $65 \mathrm{~cm}^{\wedge} 2 / \mathrm{min}$ (at the middle section $1.51 \sim 3.00 \mathrm{~mm}$ of cutting length).

Table 1. Simulated Parameters

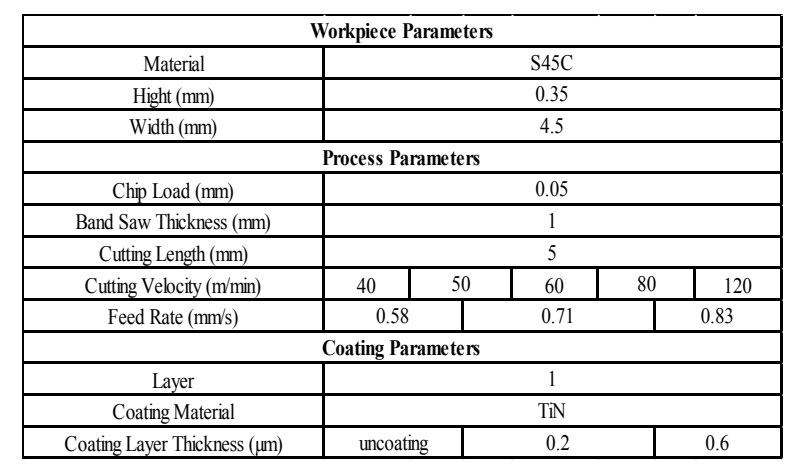
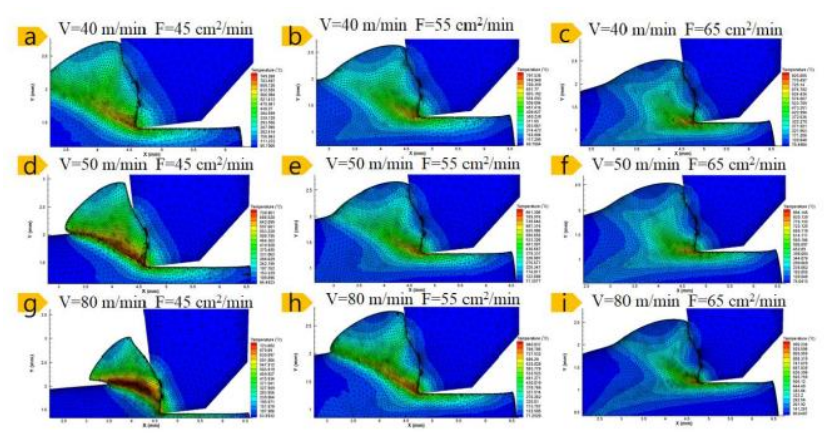

Fig.2. The cutting temperature for the relations of variations of cutting velocity from $40 \mathrm{~m} / \mathrm{min}$ to 80 $\mathrm{m} / \mathrm{min}$ and feed rate from $45 \mathrm{~cm}^{\wedge} 2 / \min$ to $65 \mathrm{~cm}^{\wedge} 2 / \mathrm{min}$ (at the middle section 1.51 3.00 mm of cutting length)

The study investigated the effect of cutting velocity from lower velocity $40 \mathrm{~m} / \mathrm{min}$ to high-speed $120 \mathrm{~m} / \mathrm{min}$. In ultra-speed sawing process, the WC tool-edge will achieve transient higher temperature $400 \mathrm{deg}$. C. In order to solve the problem under high temperature, the edge coating for adaptive coating-layer range is very important. TiN coating is an anti-wear layer to reduce the cutting temperature raising. Besides, cutting efficiency model from Eq.(22) can predict the steadystate chip formation or unsteady-state chip formation form single-cutter to multi-cutters. Obviously, (a)-(c) mean the single cutter $(V=60 \mathrm{~m} / \mathrm{min})$, the temperature on coating-layer $0.2 \sim 0.6$ is lower than single cutter of uncoating-layer; (d)-(f) mean the single cutter $(V=120 \mathrm{~m} / \mathrm{min})$; the temperature on coating-layer $0.2 \sim 0.6$ 
is lower than single cutter of uncoating-layer from Fig. 3-Fig. 5.
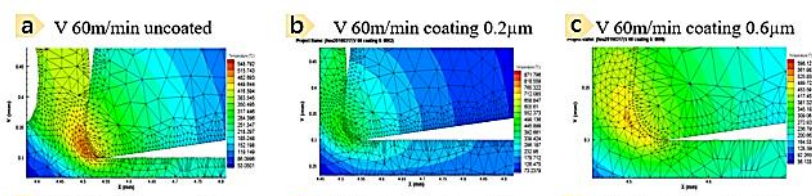

d V $120 \mathrm{~m} / \mathrm{min}$ uncoated
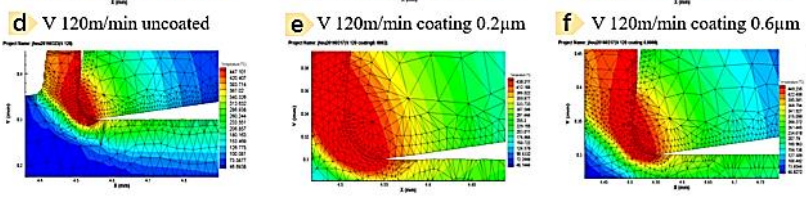

Fig.3. Temperature at section (Local $1 / 3$ length 0.00 $\mathrm{mm} 1.50 \mathrm{~mm})$; (a)-(c): single cutter $(V=60 \mathrm{~m} / \mathrm{min})$, the temperature on coating-layer $0.2 \sim 0.6 \mu \mathrm{m}$ is lower than single cutter of uncoating-layer; (d)-(f): single cutter $(V=120 \mathrm{~m} / \mathrm{min})$; the temperature on coating-layer $0.2 \sim 0.6 \mu \mathrm{m}$ is lower than single cutter of uncoatinglayer

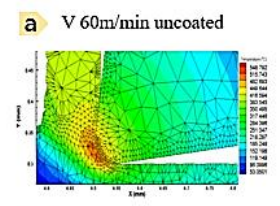

d $\mathrm{V} 120 \mathrm{~m} / \mathrm{min}$ uncoated
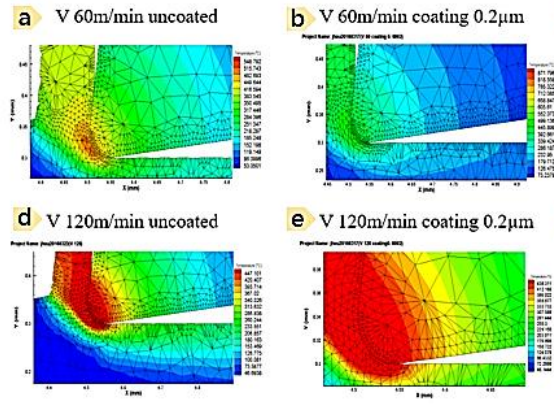

e $\mathrm{V} 120 \mathrm{~m} / \mathrm{min}$ coating $0.2 \mu \mathrm{m}$
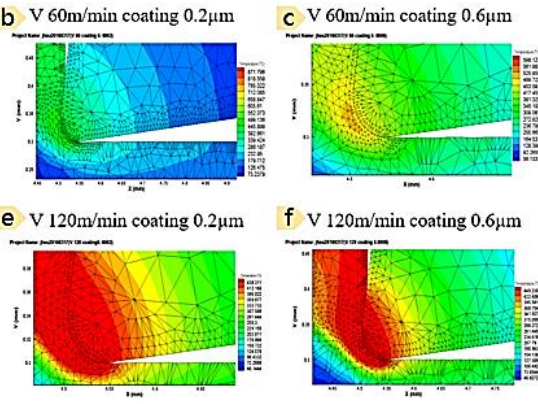

f $\mathrm{V} 120 \mathrm{~m} / \mathrm{min}$ coating $0.6 \mu \mathrm{m}$

Fig.4. Temperature at section (Local 2/3 length $1.51 \mathrm{~mm} \sim 3.00 \mathrm{~mm})$; (a)-(c): single cutter $(\mathrm{V}=60 \mathrm{~m} / \mathrm{min})$, the temperature with cutting length increasing on coating-layer $0.2 \sim 0.6 \mu \mathrm{m}$ is lower than single cutter of uncoating-layer; (d)-(f): single cutter ( $V=120 \mathrm{~m} / \mathrm{min})$; the temperature with cutting length increasing on coatinglayer $0.2 \sim 0.6 \mu \mathrm{m}$ is obviously lower than single cutter of uncoating-layer
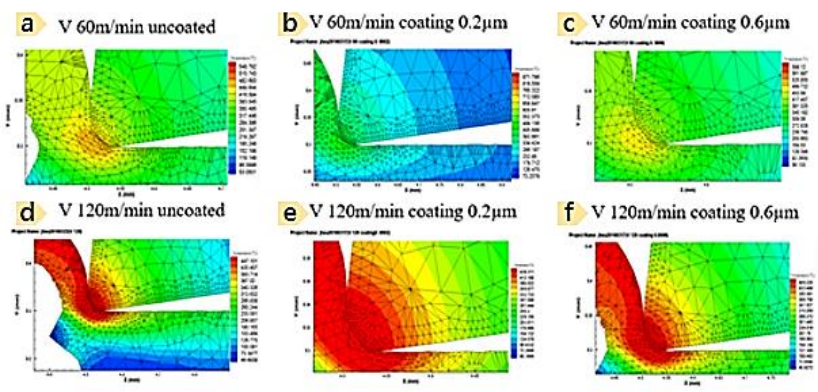

Fig.5. Temperature at section (Local $3 / 3$ length $3.01 \mathrm{~mm} 4.50 \mathrm{~mm})$; (a)-(c): single cutter $(V=60 \mathrm{~m} / \mathrm{min})$, the temperature with cutting length increasing on coating-layer $0.2 \sim 0.6 \mu \mathrm{m}$ is lower than single cutter of uncoating-layer; (d)-(f): single cutter $(V=120 \mathrm{~m} / \mathrm{min})$; the temperature with cutting length increasing on coating- layer $0.2 \sim 0.6 \mu \mathrm{m}$ is obviously lower than single cutter of uncoating-layer; temperature on cutter edge has decreasing with coating-layer increasing, and benefits for tool life.

a

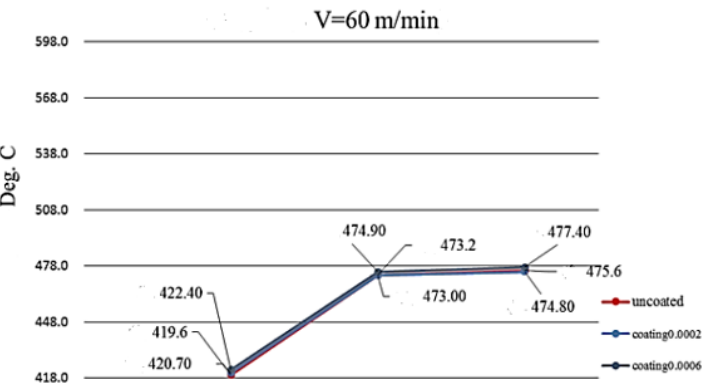

b

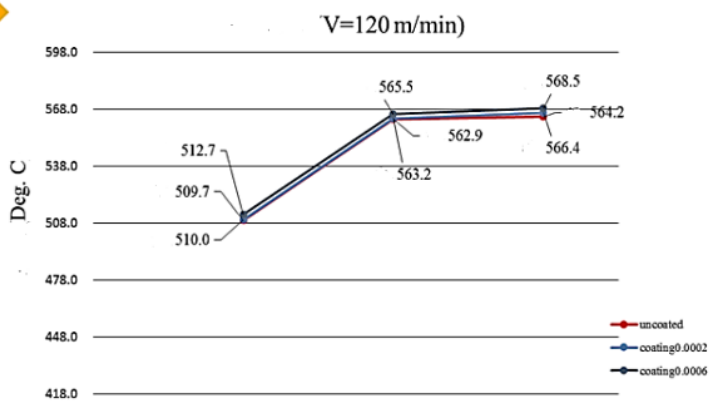

Fig.6 (a) $V=60 \mathrm{~m} / \mathrm{min}$ for single cutter; (b) $V=120 \mathrm{~m} / \mathrm{min}$ for single cutter is lower down than uncoating cutter $(0.6 \mu \mathrm{m})$
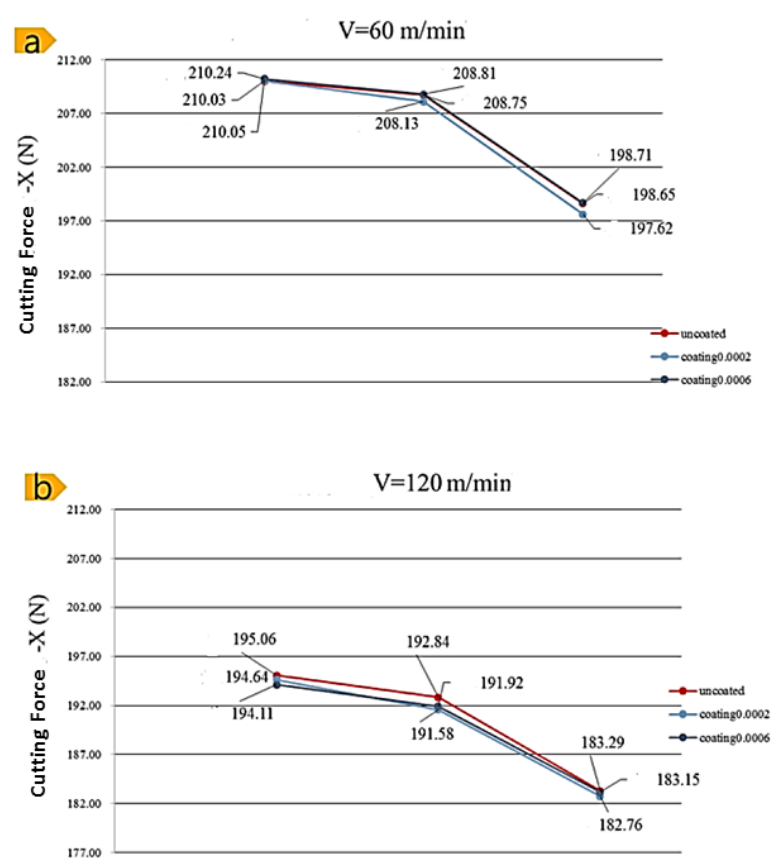


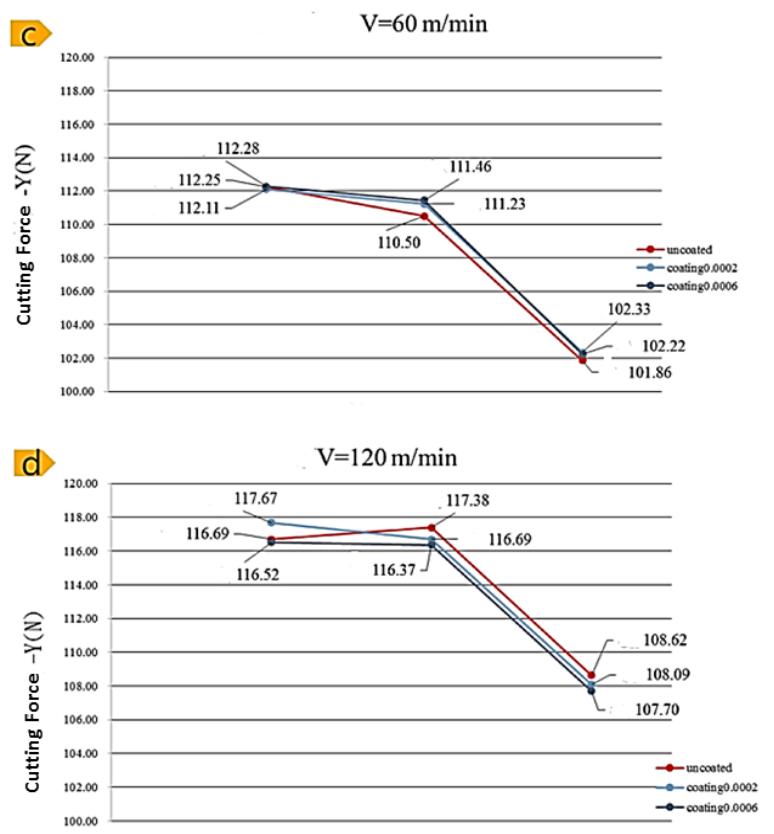

Fig.7. (a)-(b) for single cutter on $V=60 \mathrm{~m} / \mathrm{min}$ (coating0.2 0.6 $\mu \mathrm{m}$ is better than uncoating); (c)-(d) single cutter on $V=120 \mathrm{~m} / \mathrm{min}$ (coating0.6 $\mu \mathrm{m}$ ), no variation for average force

In high-speed sawing process, the cutting temperatures at different locations are different due to the contact time of tool on workpiece. The relations of cutting velocity and cutting temperature from $\mathrm{V}=60$ $\mathrm{m} / \mathrm{min}$ to $\mathrm{v}=80 \mathrm{~m} / \mathrm{min}$ have the same trends, summarized as Fig. 6. Fig. 6 (a) expressed the variation of the average cutting temperature at three sections of cutting length (420 Deg. C to 470 Deg. C); (b) means the variation of the average cutting temperature at three sections of cutting length (510 Deg. C to 560 Deg. C). Through cutting efficiency model, the cutting efficiency can be improved at least $13 \%$ by coating TiN layer 0.6 $\mu \mathrm{m}$. The average cutting force for cutting velocity 60 $\mathrm{m} / \mathrm{min}$ to $120 \mathrm{~m} / \mathrm{min}$ has the same trends for three sections of cutting length, and the cutter with coating TiN has lower cutting force than one without coating TiN as Fig. 7 (a)-(d).

To observe the simulation of stress-strain for multihook tooth design, Fig.8 expressed the first cutter of new hook-tooth design obtain the uniform cutting stress. First cutter design can simultaneously add chip thickness uniformity and lower cutter edge stress, but flank wear still existed. Shear stress from von Mises will be increasing, and it can help chip break. The maximum shear stress $933 \mathrm{MPa}$ distributed on tool-edge, reasonably. The stress $\mathrm{X}-\mathrm{X}$ and stress $\mathrm{Y}-\mathrm{Y}$ were under controlled as Fig. 8. Fig.9 shown the second cutter of new hook-tooth design in order to obtain uniform cutting stress as (a) maximum principle stress; (b) von Mises stress; (c) stress Z-Z; (d) uniform chip formation. The analysis of von Mises can find the maximum stress on tool flank, which means the flank wear will be occurred in high-speed dynamics. Due to Fig. 9 (d), the hook- tooth design indeed produced the better uniform chip formation, continuously. a. Von Mises Stress

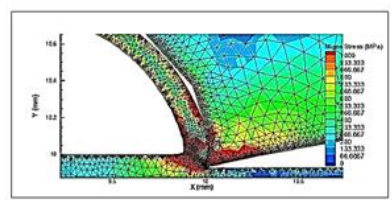

c. Stress $\mathrm{X}-\mathrm{X}$

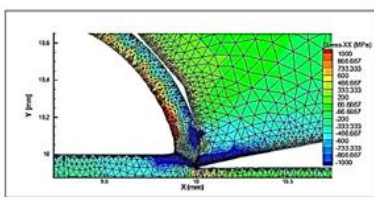

b. Maximum Shear Stress

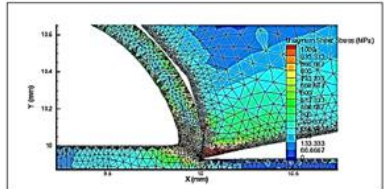

d. $\quad$ Stress $Y-Y$

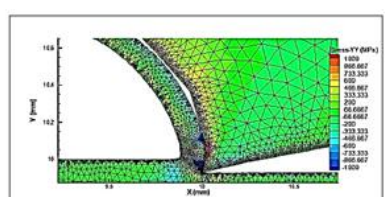

Fig. 8. First cutter of new hook-tooth design in order to obtain uniform cutting stress; (a) von Mises stress; (b) maximum shear stress; (c) stress X-X; (d) stress Y-Y a. Maximum Principle Stress

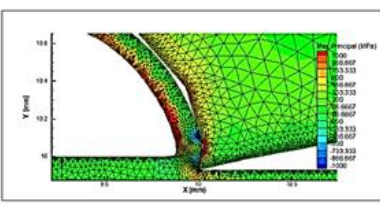

c.

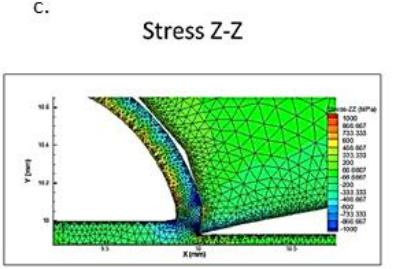

b. Von Mises Stress

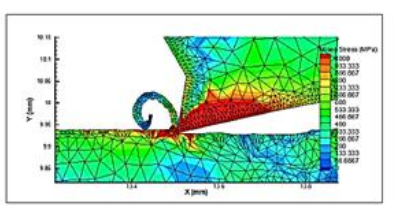

Chip Formation by Second Cutter

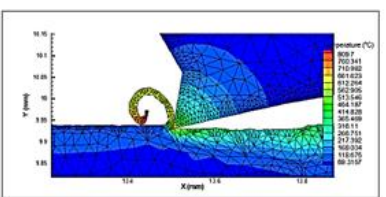

Fig.9. Second cutter of new hook-tooth design in order to obtain uniform cutting stress; (a) maximum principle stress; (b) von Mises stress; (c) stress Z-Z; (d) uniform chip formation

\subsection{Vibration and Frequency Response in High- Speed Sawing Process}

The mainly measured locations were on S45C first, middle and last sections, and the values were expressed as vibration energy RMS. The RMS increased with cutting velocity increasing. The acceleration gages No.3 and No.4 had larger vibration RMS, because the locations were on cut-out, where the stiffness was not enough strong. The middle section on S45C has larger vibration because of the longest cutting length. The experimental vibration trends agreed well with the simulated cutting force profile as Fig. 10 (a), and the average cutting force distributed on $400 \mathrm{~N} \sim 500 \mathrm{~N}$. Through a new tooth design, the smooth frequency response can be achieved as Fig. 10 (b). 


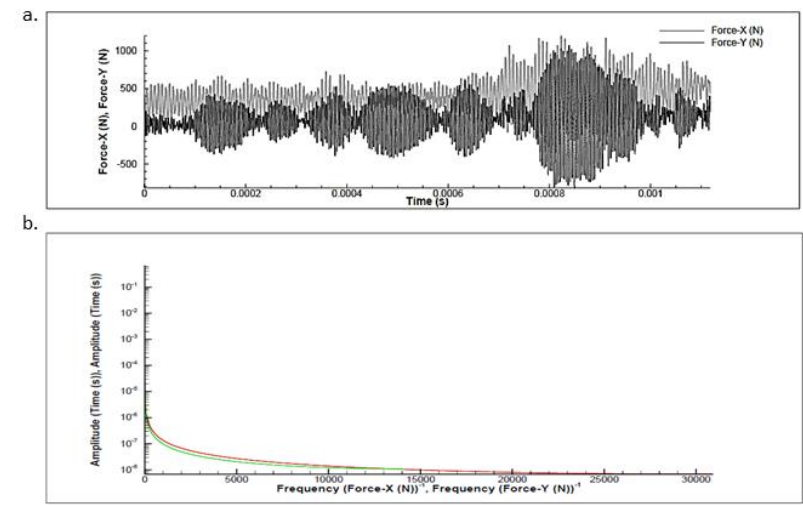

Fig.10. (a) Two-dimensional cutting force for new hooktooth has better uniformity; (b) smooth frequency response

The validation used the 4 acceleration gages to measure the vibration (Fig. 12 -Fig. 13) compared with the simulated vibration and frequency reponse (Fig. 10Fig. 11) has nicely trends from the three sections on S45C. Experimental preparation as Fig. 12 (a) the location for No.1 to No.4 acceleration gage and S45C for first, middle and last section ; (b) COSEN company C$320 \mathrm{GNC}$; (c) PCB352C22 acceleration gage (d) NI9234 vibration sampling device.

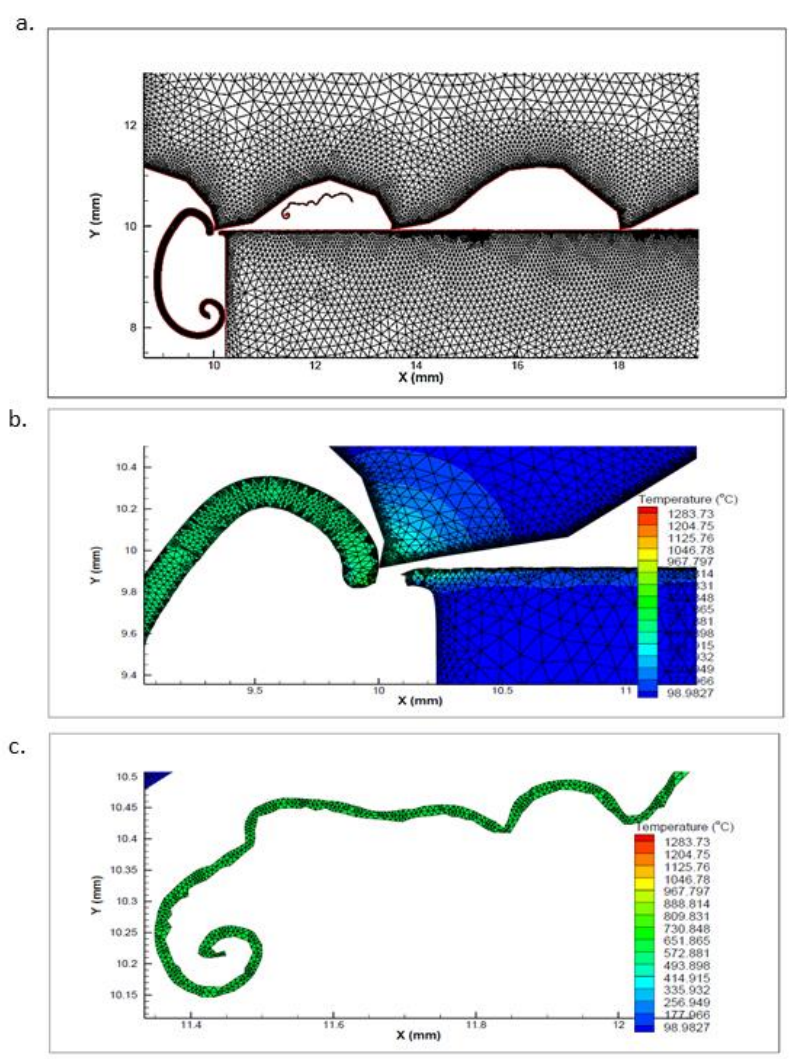

Fig.11. (a) Simulation of new hook-tooth design in order to obtain uniform cutting stress; (b) Burr for cutting out and uniform temperature distribution on chip surface (c) second chip temperature uniformity and continuous chip formation;
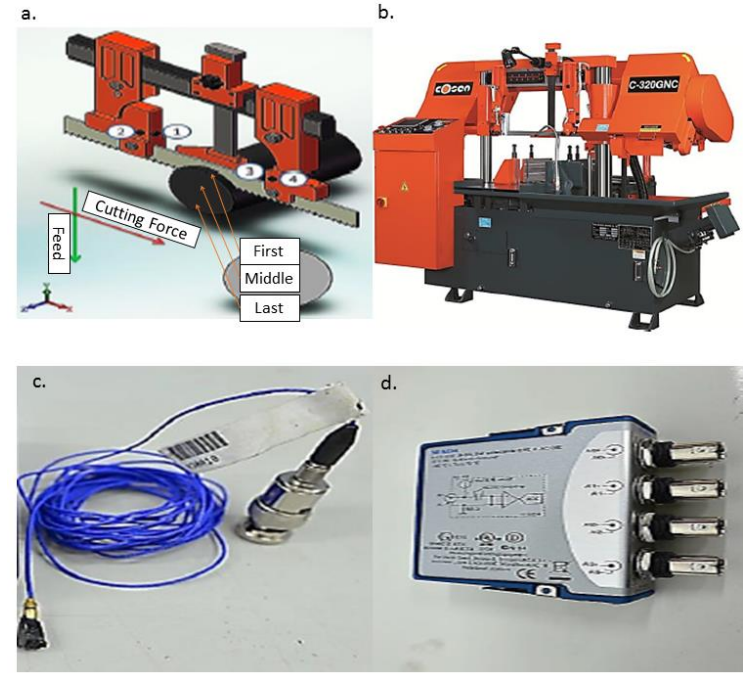

Fig.12. Experimental measurement device; (a) the location for No. 1 to No.4 acceleration gage and S45C for first, middle and last section ; (b) COSEN company C320GNC band-saw machine ; (c) PCB352C22 acceleration gage (d) NI-9234 vibration sampling device; a

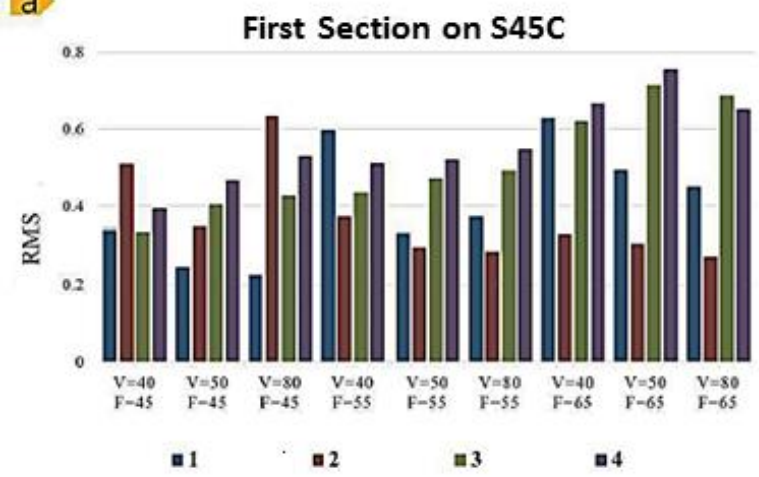

Ib

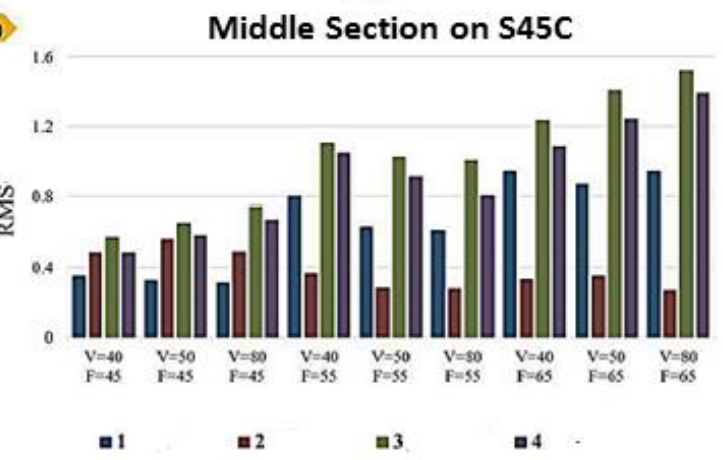

C

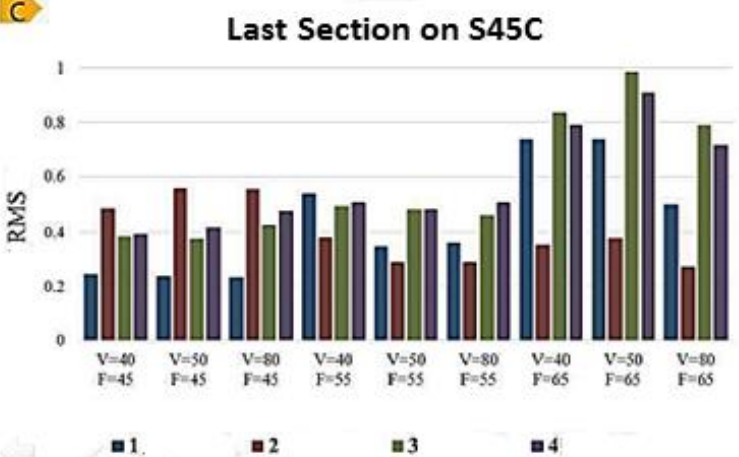


Fig.13. Vibration RMS on S45C first, middle and last section; the experimental results compared with the cutting force profile (Fig, 10 (a)) has the same trends from first, middle and last section on S45C

\subsection{Chip Thickness Uniformity and Chip Temperature Uniformity}

Simulation of new hook-tooth design can achieve chip thickness uniformity and chip temperature uniformity, simultaneously. To observe from Fig. 11, chip shape is an important feature. The chip formation from first cutter was nicely uniform and continuou. While the tool cutting out, the burr will be occurred on S45C. The chip surface temperature was about 500 deg.C, and the advantages of hook-tooth included that,

1. Good Surface Roughness

2. Good Cutting Force Distribution

3. Nice Chip Formation in High-Speed Sawing Process

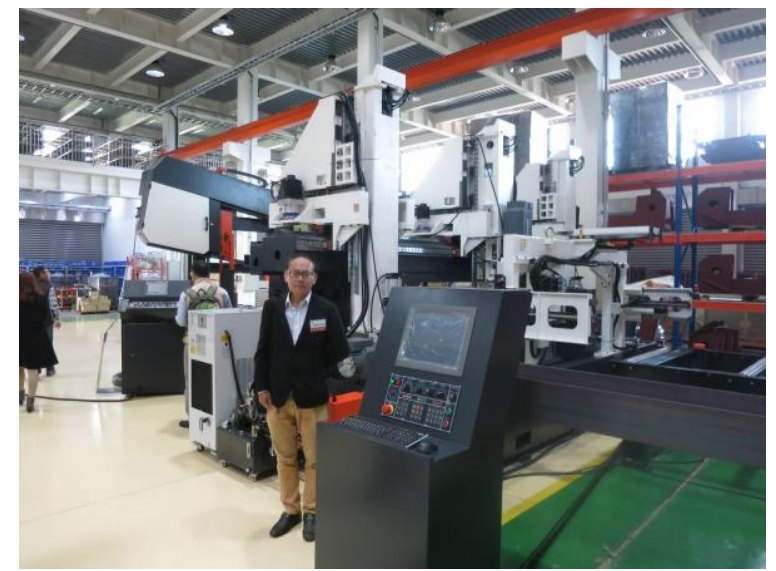

Fig.14 The author Prof. Sung-Hua Wu stood around the COSEN Band-Saw Machine for MOST plan

The study can simulated the residual temperature about 256 deg.C on S45C. From the second cutter, it can occur the second chip temperature uniformity and continuous chip formation. The tooth design and coating under process parameters in high-speed sawing can be achieved the COSEN plan propurse (Fig. 14). By cutting mechanism adjusting, the MMR will be raising and tooth-bite improvement for future work.

\section{Conclusions}

The finding results in the study has been summarized as follows,

1. The study proposed the chip formation steady-state model and cutting efficiency model for multi-cutters by Taylor tool life and fractal equation according to uniform chip thickness in high-speed band sawing process.

2. The simulation successfully processed the band-saw orthogonal cutting by Lagrangian finite element method and numerial analysis.
3. Through cutting efficiency model, the cutting efficiency can be improved at least $13 \%$ by coating TiN layer 0.6 . The average cutting force for cutting velocity $60 \mathrm{~m} / \mathrm{min}$ to $120 \mathrm{~m} / \mathrm{min}$ has the same trends for three sections of cutting length, and the cutter with coating TiN has lower cutting force than one without coating TiN.

4. The study can simulated the residual temperature about 256 deg.C on S45C. From the second cutter, it can occur the second chip temperature uniformity and continuous chip formation.

5. The tooth design and coating under process parameters in high-speed sawing can be achieved the COSEN plan propurse.

6. First cutter design can simultaneously add chip thickness uniformity and lower cutter edge stress, but flank wear still existed. The maximum shear stress $933 \mathrm{MPa}$ distributed on tool-edge, reasonably. The stress $\mathrm{X}-\mathrm{X}$ and stress $\mathrm{Y}-\mathrm{Y}$ were under controlled

7. If the chip formation is steady-state, the differentialcutter angle is uaually constant.

8. For two dimensional orthogonal cutting, the MDOF cutting dynamics has been established on the study. In additions, the tool life equation can effectively predict the cutting performance of the band saw in order to improve the process efficiency and served as the reference of actual machining process.

9. While the hook- tooth cutting speed achieved 60 $\mathrm{m} / \mathrm{min}$, comparing with non-coating cutting tooth, coating $0.2 \sim 0.6 \mu \mathrm{m}$ was the highest temperature decreased obviously and the cutting force of hooktooth also decreased.

10. The research put forward the cutting factors of the geometric structure of the band saw cutter, simulated and improved the processing characteristics during the cutting process, the impact of different cutting types by taking advantages of different process parameters, such as coating parameters, cutting speed and cutting feed.

This work was supported in part by Taiwan NSC under Grant No. MOST 105-2221-E-327 -015, and the industril plan -Development of Ultra Speed Intelligent CNC Band Saw Machine from No.105RB07. Appreciation is expressed to the COSEN Company for the provision of the band-saw and for its subsequent contribution to the success of this study. Additional thanks to Prof. Sheng-Jye Hwang, Prof. Ta-Hui Lin and Prof. Rong-Shean Lee at NCKU for the supporting in studied process. Besides, external thinks to Prof. Yunn-Lin Hwang and Prof. Jeng-Haur Horng for the research cooperation at National Formosa University.

\section{References}

[1] T.J. Ko, H.S. Kim, Mechanistic cutting force model in band sawing, Int. J. Mach. Tool. \& Manu., 39, 8,118-119 (1999)

[2] C. Andersson, M.T Andersson, J.-E Ståhl, Bandsawing. Part I: cutting force model including effects 
of positional errors, tool dynamics and wear, Int. J. Mach. Tool. \& Manu., 41, 227-236 (2001)

[3] C. Andersson, J.-E S.H. Hellbergh, Bandsawing. Part II: detecting positional errors, tool dynamics and wear by cutting force measurement, Int. J. Mach. Tool. \& Manu., 41, 237-253 (2001)

[4] C. Andersson, Bandsawing. Part III: stress analysis of saw tooth microgeometry, Int. J. Mach. Tool. \& Manu., 41, 255-263 (2001)

[5] T.D. Marusich, E. Askari, Modeling Residual Stress and Workpiece Quality in Machined Surfaces, Proceedings of the 4th CIRP International Workshop on Modelling of Machining Operations, Delft, The Netherlands, 105-109 (2001)

[6] X. Xu, Y. Yu, Sawing performance of diamond with alloy coatings, Surf. \& Coat. Tech., 198, 459- 463 (2005)

[7] R. Okai, S.J. Mitchual, K. Frimpong-Mensah, Optimization techniques for minimizing saw teeth deflection and lumber thickness variation, Prec. Eng., 30, 1, 39-46 (2006)

[8] I.S. Buyuksagis, Effect of Cutting Mode on the Sawability of Granites Using Segmented Circular Diamond Sawblade, Int. J. Mach. Tool. \& Manu., 183, 399-406 (2007)

[9] Sung-Hua Wu, J.-J. Junz Wang, R. S. Lee, Chip fractal geometry and loading characteristics of sinusoidal multi-cutters in hack-sawing process, Int. J. Mach. Tool. \& Manu., 111, 68. Corrigendum (2016)

[10] T. Thaler, P. Potocnik, I. Bric, E. Govekar, Chatter detection in band sawing based on discriminant analysis of sound features, Appl. Acou., 77,114-121 (2014)

[11] T. Thaler, B. Krese, E. Govekar, Stability diagrams and chatter avoidance in horizontal band sawing, CIRP Anna.-Manu. Tech., 64, 81-84 (2015)

[12] T.G. Kumbera, J.A. Patten, H.P. Cherukuri, C.J. Brand, T.D. Marusich, Numerical simulations of ductile machining of silicon nitride with a cutting tool of defined geometry, Int. J. Mach. Tool. \& Manu., 5, 341352 (2001)

[13] T.D. Marusich, J.D. Thiele, C.J. Brand, Simulation and analysis of chip breakage in turning processes, Technical Paper Presented in Caterpillar Inc, 1-10 (2001)

[14] W. Grzesik, M. Bartoszuk, P. Nieslony, Finite element modelling of temperature distribution in the cutting zone in turning processes with differently coated tools, J. Mate. Proc. Tech., 1204-1211 (2005)
[15] G. Fang, P. Zeng, Three-dimensional thermoelastic-plastic coupled FEM simulations for metal oblique cutting processes, J. Mate. Proc. Tech., 168, 1, 42-48 (2005)

[16] T.D. Marusich, S. Usui, S. Lankalapalli, N. Saini, L. Zamorano, A. Grevstad, Residual Stress Prediction for Part Distortion Modeling, Copyright SAE International (2006)

[17] T.D. Marusich, S. Usui, J. Ma, D.A. Stephenson, A. Shih, Finite Element Modeling of Drilling Processes with Solid and Indexable Tooling in Metals and Stackups (2007)

[18] M. Mohammadpour, M.R. Razfar R. Jalili Saffar, Numerical investigating the effect of machining parameters on residual stresses in orthogonal cutting, Simu. Mode. Prac. \& Theo., 18, 3,378-389 (2010)

[19] K. Huang, W. Yang, Analytical model of temperature field in workpiece machined surface layer in orthogonal cutting, J. Mate. Proc. Tech., 229, 375-389 (2016)

[20] B.B. Mandelbort, The fractal geometry of nature, W.H. Freeman, New York (1982) 